\title{
ANÁLISE COMPARATIVA ENTRE CORANTES NATURAIS (URUCUM) E ARTIFICIAIS
}

\author{
A. P. CORDOVA ${ }^{1}$, B. S. SOUZA ${ }^{1}$, H. CASTRO ${ }^{1}$, M. C. DAMÁSIO ${ }^{1}$, C. A. ALVES Jr. ${ }^{1}$ \\ 1 Serviço Nacional de Aprendizagem Industrial - SENAI - Unidade Joinville Norte, \\ Departamento de Química \\ E-mail para contato: eq.carlos@gmail.com
}

\begin{abstract}
RESUMO - A indústria têxtil teve um papel importante no desenvolvimento das civilizações, desde a manufaturas de tecidos, que acontece desde antes de Cristo, até os dias atuais. O desenvolvimento de corantes sintéticos permitiu a produção de inúmeras tonalidades de fibras tingidas, porém o efluente gerado é de difícil tratamento, e já causou inúmeros impactos ambientais devido a fatores, como despejo indevido e acidentes industriais. Este trabalho teve por objetivo comparar a qualidade do tingimento em tecidos de algodão com um corante natural extraído do urucum, e um sintético (laranja Sidercrom). Após o tingimento, foram feitas análises de cor e também a solidez à lavagem, com o auxílio de um espectrofotômetro X-Rite CA22 e do software Helios v. 3.1. Os resultados mostraram que o tecido tingido com corante natural não apresentou variações em sua tonalidade perceptíveis ao olho nu frente a diferentes tipos de iluminante, além de apresentar uma ótima resistência no teste de solidez à lavagem.
\end{abstract}

\section{INTRODUÇÃO}

As cores sempre despertaram interesse aos homens. Acredita-se que os corantes começaram a ser utilizados na Índia há mais de 4.000 anos em cerâmicas, couros e tecidos. Povos antigos, como os egípcios, possuem indícios de tecidos coloridos utilizados em suas múmias.

É inegável a importância dos corantes na história do Brasil. O pau-brasil, árvore que fornece corantes nas cores vermelho, rosa e marrom, foi a primeira atividade econômica realizada pelos portugueses em território brasileiro.

O tingimento, atualmente aplicado em indústrias têxteis, abrange a área dos corantes. Joinville é um polo industrial de Santa Catarina, onde se concentram importantes indústrias têxteis que aplicam os corantes na fabricação de seus produtos. Essas indústrias tem um papel fundamental na economia da cidade. Entretanto, é preciso ter um devido cuidado uma vez que o descarte inapropriado de corantes afeta a vida local.

De acordo com Fennema (2000), corante pode ser definido como qualquer substância química, natural ou sintética, que confira uma determinada cor. O corante artificial é proveniente do petróleo. Esse é um líquido escuro que possui um grande número de compostos orgânicos em sua composição, sendo grande parte deles hidrocarbonetos, compostos formados por carbono $(\mathrm{C})$ e hidrogênio $(\mathrm{H})$, utilizados nos corantes (ROCHA et al., 2009). 
Os principais intermediários, provenientes do petróleo, utilizados nos corantes são a anilina $\left(\mathrm{C}_{6} \mathrm{H}_{5} \mathrm{NH}_{2}\right)$, o cumeno $\left(\mathrm{C}_{9} \mathrm{H}_{12}\right)$, ciclo-hexano $\left(\mathrm{C}_{6} \mathrm{H}_{12}\right)$, fenol $\left(\mathrm{C}_{6} \mathrm{H}_{6} \mathrm{O}\right)$ e o ácido salicílico $\left(\mathrm{C}_{7} \mathrm{H}_{6} \mathrm{O}_{3}\right)$, compostos orgânicos presentes também nos processos de fabricação de outras áreas químicas. Para produzir os intermediários, utilizam-se conversões químicas. Destacam-se a de halogenação e a nitração.

Já, para Menda (2014), o corante orgânico natural é obtido por fontes vegetais ou animais. $\mathrm{Na}$ indústria alimentícia, os principais corantes naturais usados são os extratos de urucum (Bixa orellana), carmim de cochonilha (Dactylopiuscoccus), curcumina, antocianinas e as betalaínas.

Existem quatro tipos de classes de corantes, sendo que as de maior destaque são: diretos, reativos e sulfurosos. A classe abordada neste artigo é a dos reativos.

A principal aplicação dessa classe é em fibras de celulose (como a do algodão), pois reagem com a fibra através de ligações covalentes, em meio alcalino. O corante reage com as hidroxilas $(-\mathrm{OH})$ ligadas à celulose, podendo então reagir com outras hidroxilas (como as da água). Essa reação chama-se de hidrólise, e deve ser controlada (SENAI, 2004).

Entre os diversos tipos de corantes naturais destaca-se o urucum, que conforme Franco (2008), é aplicado como corante em alimentos como produtos lácteos, embutidos, doces, licores, sorvetes e margarinas.

A fibra utilizada para realizar o trabalho foi a de 100\% algodão. Segundo Kassab (1986), o algodão (Gossypium spp.) é uma fibra natural de origem vegetal, fina, de comprimento variável e que não se restringe muito ao clima e solo, pode assim, ser cultivado em quase todos os continentes.

\section{MATERIAIS E MÉTODOS}

\subsection{Preparação do urucum}

O urucum utilizado neste experimento foi colhido de um urucuzeiro, pertencente à família das Bixáceas, localizada na cidade de Ivinhema - MS.

Como a película exterior das sementes do urucum fornece a coloração, foi aberto o fruto para coletá-las. As sementes foram primeiramente peneiradas, para a remoção de quaisquer resquícios da casca do urucum, e posteriormente pesadas em uma balança semianalítica BEL ${ }^{\circledR}$, obtendo-se 120,023 g de urucum.

Para o preparo do corante, Ferreira (1998) indica a diluição de $400 \mathrm{~g}$ de sementes de urucum em $7 \mathrm{~L}$ de água, para $1 \mathrm{~kg}$ de fibras. Contudo, como foram utilizados apenas 91,573 $\mathrm{g}$ de algodão, fez-se uso de 36,629 g de semente. Depois, colocaram-se as sementes sem impurezas em um cadinho e adicionaram-se 3,6 $\mathrm{g}$ de cloreto de sódio $(\mathrm{NaCl})$ juntamente com $100 \mathrm{~mL}$ de água $\left(\mathrm{H}_{2} \mathrm{O}\right)$ e $40 \mathrm{~mL}$ de álcool etílico $\left(\mathrm{C}_{2} \mathrm{H}_{5} \mathrm{OH}\right) 92,8 \%$. Transferiu-se o conteúdo do cadinho para a panela de alumínio e foram adicionados $2,1 \mathrm{~L}$ de água. A mistura foi aquecida em uma chapa de aquecimento QUIMIS ${ }^{\circledR} \mathrm{Q} 313 \mathrm{~A}$, a $110^{\circ} \mathrm{C}$, para evaporação do álcool. 
Após 15 minutos de fervura, retirou-se a mistura restante para a realização de uma filtração simples, com filtro de papel.

\subsection{Preparação do mordente}

O mordente escolhido para o procedimento foi o alúmen de potássio $\left(\mathrm{KAl}\left(\mathrm{SO}_{4}\right)_{2}\right)$. De acordo com Ferreira (1998), a relação entre a quantidade de mordente e de urucum empregadas é de $150 \mathrm{~g}$ e $400 \mathrm{~g}$, respectivamente. A proporção entre a quantidade de mordente e $\mathrm{H}_{2} \mathrm{O}$ é de $150 \mathrm{~g}$ e $18 \mathrm{~L}$, respectivamente. Com esses dados, foram adicionados $45 \mathrm{~g}$ de $\mathrm{KAl}\left(\mathrm{SO}_{4}\right)_{2}$ em 5,4 $\mathrm{L}$ de $\mathrm{H}_{2} \mathrm{O}$, e posteriormente a solução foi aquecida, para promover a solubilização do alúmen. Em seguida, mergulhou-se a fibra para ser fervida a $45^{\circ} \mathrm{C}$ durante 30 minutos.

\subsection{Tingimento com corante natural}

Com o mordente aplicado ao tecido e o corante filtrado, pôs-se os dois na panela, acrescentando 3,3 L de água. Como já foram adicionados 2,1 $\mathrm{L}$ de $\mathrm{H}_{2} \mathrm{O}$ anteriormente, o volume necessário para se completar o volume total $(5,4 \mathrm{~L})$ é de 3,3 L. Imergiu-se a fibra na solução em aquecimento e manteve-se o sistema a uma temperatura de $90^{\circ} \mathrm{C}$ durante aproximadamente $1 \mathrm{~h}$. A Figura 1 mostra o processo de tingimento.

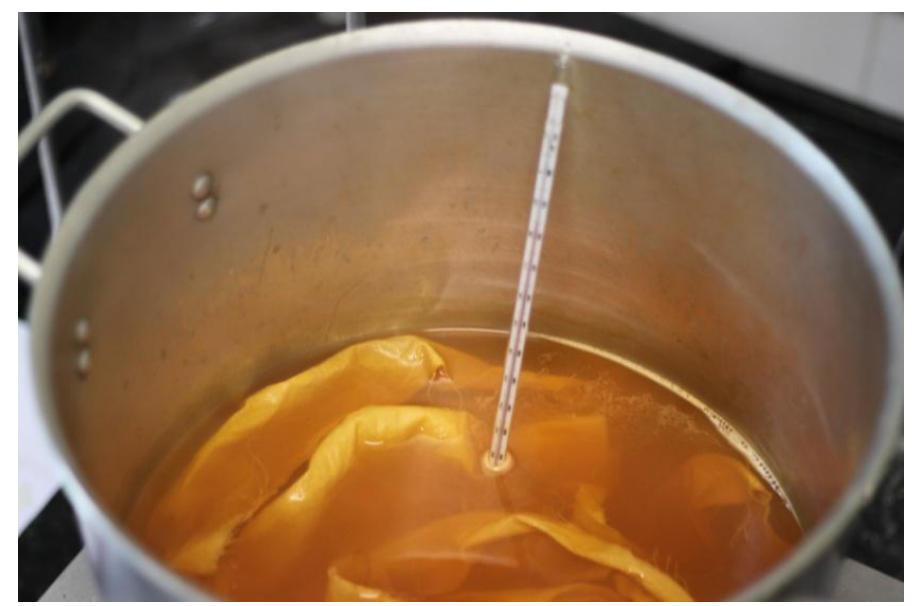

Figura 1 - Processo de tingimento. Fonte: os autores (2013).

Após $1 \mathrm{~h}$ de aquecimento, retirou-se a fibra da panela. Seguindo o procedimento, lavou-se a fibra com água corrente, com pequenas doses de ácido acético (vinagre) e sal (100 $\mathrm{mL}$ de vinagre para 3,6 $\mathrm{g}$ de $\mathrm{NaCl}$ ). Após torcer o tecido, o mesmo foi colocado para secar ao ar livre por aproximadamente $18 \mathrm{~h}$.

Para realizar o tingimento com o carente artificial, utilizou-se a escala Pantone para escolher o corante mais próximo do natural. A cor escolhida para análise possui tom pastel e é codificado como "13-1027 TPX" e nomeada Apricot Cream. Através dessa enumeração, encomendou-se o corante com a empresa Siderquímica, todavia, essa não trabalhava com a Escala Pantone, sendo assim, enviou uma tonalidade similar: Laranja Sidercron. 


\subsection{Tingimento com corante artificial}

No processo de preparar a fibra com mordente utilizou-se a mesma quantidade de alúmen de potássio para a mesma quantia de água. Respectivamente $45 \mathrm{~g} \mathrm{e} \mathrm{5,4} \mathrm{L.} \mathrm{A} \mathrm{fibra}$ banhada nessa solução ficou durante 30 minutos a $90^{\circ} \mathrm{C}$. Diluiu-se inicialmente $24,037 \mathrm{~g}$ de corante artificial em 4,1 L de água. Como a tonalidade estava muito escura, retirou-se $1 \mathrm{~L}$ de solução para diminuir a concentração, e em seguida acrescentou-se 2 L de água para alcançar um laranja mais claro. Durante $1 \mathrm{~h}$, a fibra ficou imersa nessa solução a $90^{\circ} \mathrm{C}$.

Ao se retirar a fibra do tingimento foi realizada sua lavagem com água corrente, sal $(3,6 \mathrm{~g})$ e vinagre $(100 \mathrm{~mL})$.Após a lavagem deixou-se o tecido tingido secar durante $18 \mathrm{~h}$ ao ar livre.

\subsection{Análises}

Após os tingimentos, realizaram-se análises comparativas entre as fibras tingidas natural e artificialmente. Para realizar a análise de cor, utilizou-se o aparelho de espectrofotômetro (modelo X-Rite CA22), e as medições foram feitas por meio do software Helios v. 3.1. A análise de cor apresenta dados sobre a composição da cor fixada no tecido, a quantidade e intensidade das cores primárias e/ou de verde que formam a cor visualizada. As análises apresentam valores diferentes para cada tipo de luz em que o tecido é exposto. Essas luzes dividem-se em: luz solar (D65/10), luz fluorescente (TL84/10) e luz incandescente (A/10) (TEXCONTROL, 2014). Para cada iluminante, o tecido apresentará modificação na tonalidade da cor visualizada.

Para fazer a medição das análises, o aparelho usa como base o modelo CIE/LAB, representado na Figura 2.

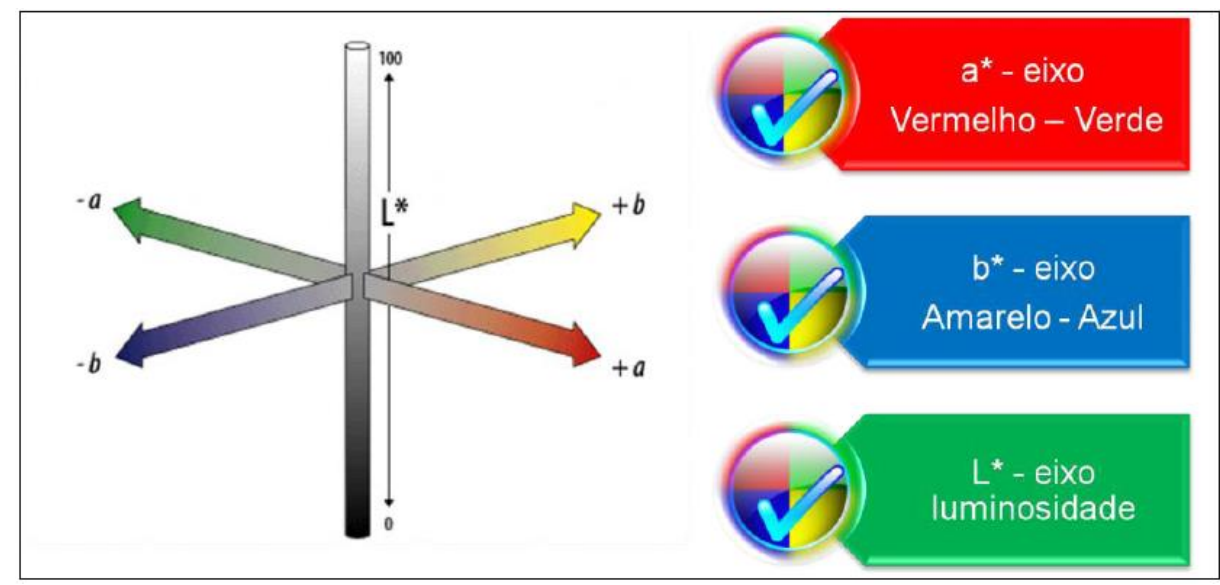

Figura 2 - Modelo CIE/LAB. Fonte: Disponível em:

<http://sellerink.com.br/blog/tag/modelo-cielab>. Acesso em 26 abr. 2014.

Na Figura 2, o eixo $\mathrm{L}^{*}$ representa o quão claro/escuro é o tecido. Se o valor de $\mathrm{L}$ for negativo ou próximo de zero, o tecido tem uma tonalidade mais escura, já se for positivo ou mais próximo de 100 , a tonalidade do tecido será mais clara. O eixo $a^{*}$ apresenta a quantidade de vermelho (+a) ou verde (-a) que a amostra analisada possui. Já o eixo b* indica a tonalidade de amarelo $(+b)$ ou azul $(-b)$ presente na amostra analisada. 
Primeiramente, foram feitas três medições da cor selecionada na Escala Pantone. Em seguida, mediu-se a cor do tecido tingido com corante natural (em triplicata). Fez-se o mesmo procedimento com o tecido tingido com corante artificial. Essas três medições geraram uma média para após realizar as análises. Tais análises permitiram a conclusão de qual corante estava mais próximo da Escala Pantone e mostraram a capacidade do corante em continuar tendo a mesma tonalidade em diferentes luzes.

Também se realizou análise de solidez à lavagem, adaptado da NBR ISO 105-A01 (2006). No teste, foi cortado um pedaço $(100 \mathrm{x} 40 \mathrm{~mm})$ do tecido tingido (corante natural e artificial) e dois tecidos testemunha (100\% algodão cru), um para cada tingimento. Cada tecido tingido, juntamente com seu tecido testemunha, foi colocado em um recipiente contendo solução de sabão neutro ( $5 \mathrm{~g} / \mathrm{L}$ de sabão comercial). As amostras permaneceram em repouso durante 30 minutos, enquanto o sabão agia sobre os tecidos, simulando uma lavagem. A Figura 3 mostra os tecidos imersos nas soluções de sabão neutro no início do teste.

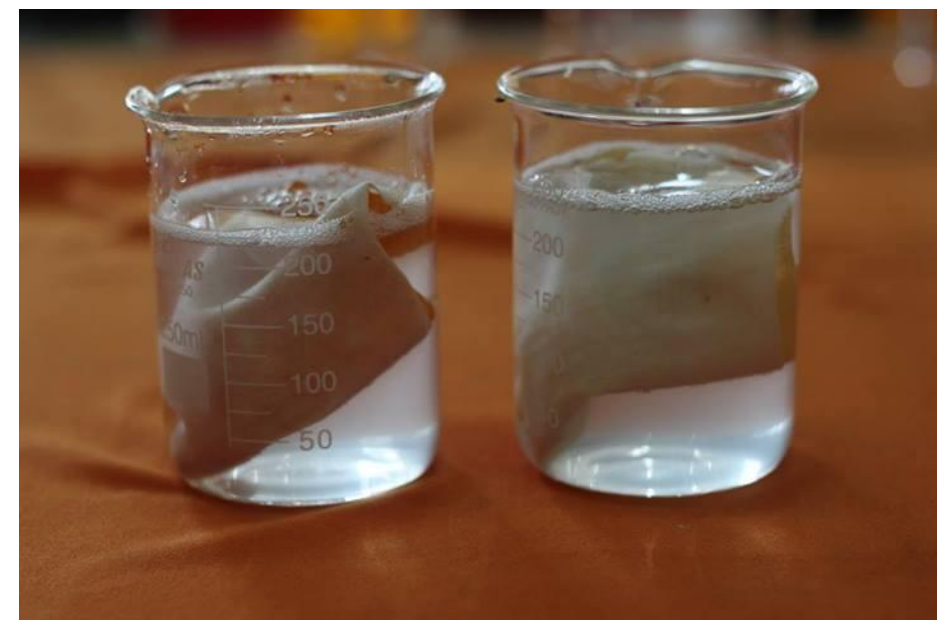

Figura 3 - Início do teste de solidez à lavagem. Fonte: os autores (2013).

Após o tempo, as amostras foram centrifugadas e depois colocadas para secar. Com as amostras secas, fez-se a análise visual e quantitativa com o espectrofotômetro dos tecidos testemunha, com três medições, dando ênfase às partes com tonalidades mais intensas.

\section{RESULTADOS E DISCUSSÃO}

\subsection{Cor}

Os resultados obtidos com os tecidos tingidos são apresentados nas Tabelas 1 (corante artificial) e 2 (corante natural). Do lado dos valores obtidos, são indicadas as tonalidades analisadas pelo equipamento.

Tabela 1 - Análise quantitativa e qualitativa do corante artificial

\begin{tabular}{|c|c|c|c|}
\cline { 2 - 4 } \multicolumn{1}{c|}{} & D65/10 & TL84/10 & A/10 \\
\hline $\mathbf{d L}^{*}$ & $-13,47$ (escuro) & $-12,46$ (escuro) & $-12,21$ (escuro) \\
\hline $\mathbf{d a}^{*}$ & 8,55 (avermelhado) & 7,84 (avermelhado) & 9,81 (avermelhado) \\
\hline $\mathbf{d b}^{*}$ & 10,20 (amarelado) & 12,29 (amarelado) & 11,75 (amarelado) \\
\hline
\end{tabular}


Tabela 2 - Análise quantitativa do corante natural

\begin{tabular}{|c|c|c|c|}
\cline { 2 - 4 } \multicolumn{1}{c|}{} & $\mathbf{D 6 5 / 1 0}$ & TL84/10 & A/10 \\
\hline dL* $^{*}$ & $-3,59$ (escuro) & $-3,54$ (escuro) & $-3,98$ (escuro) \\
\hline da* $^{*}$ & $-1,07$ (esverdeado) & $-1,22$ (esverdeado) & $-0,20$ (esverdeado) \\
\hline db* $^{*}$ & $-5,96$ (azulado) & $-5,82$ (azulado) & $-6,77$ (azulado) \\
\hline
\end{tabular}

O corante artificial apresentou grande variação de tonalidade para as diferentes luzes utilizadas na análise. Essas variações podem ser perceptíveis a olho nu. Com a luminosidade houve uma pequena variação na tonalidade do corante natural, que não pode ser visível a olho nu.

\subsection{Solidez à lavagem}

Após o teste de solidez à lavagem, foi possível notar a diferença entre os dois tingimentos. A fibra tingida com o corante natural não alterou a cor da água, já o corante artificial tornou o meio e o tecido-testemunha alaranjados, devido à reação fibra-corante e à reação água-corante. A Figura 4 mostra o comparativo visual entre a água de lavagem empregada no tecido artificial (esquerdo) e natural (direito).

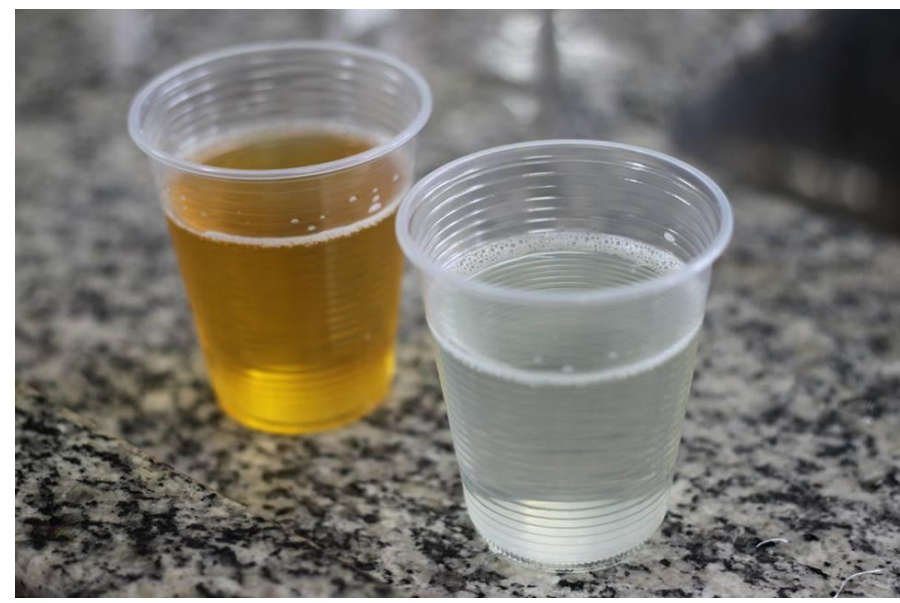

Figura 4 - Amostra das águas de lavagem dos tecidos com corante natural e artificial. Fonte: os autores (2013).

Os tecidos-testemunha testados também foram analisados no espectrofotômetro, para avaliar o comportamento do tingimento. A comparação entre os tecidos é feita em uma escala entre 1 e 5, onde 1 significa que nem todo o corante aderiu à fibra; enquanto o 5 indica que não há excesso de corante e que esse aderiu totalmente à fibra (NBR ISO 105-A02 e A03, 2006). Os valores aceitos pelas indústrias têxteis são maiores ou igual a 3 , o que indica que até pode haver excesso de corante, mas isso não causará problemas em outras peças que forem lavadas juntamente com esse tecido. Os resultados obtidos pelo corante artificial encontram-se na Tabela 3, e os do corante natural na Tabela 4.

Tabela 3 - Análise de solidez à lavagem do corante artificial

\begin{tabular}{|c|c|}
\hline NOTA & INTERVALO \\
\hline 2,70 & $2-3$ \\
\hline
\end{tabular}


Tabela 4 - Análise de solidez à lavagem do corante natural

\begin{tabular}{|c|c|}
\hline NOTA & INTERVALO \\
\hline 4,52 & $4-5$ \\
\hline
\end{tabular}

O corante artificial teve um valor abaixo do exigido pelas empresas, sendo assim, havia excesso de corante na fibra tingida. Uma das possibilidades do corante artificial estar em excesso é a má lavação após o tingimento; ou a má diluição do corante durante o tingimento.

O corante natural teve um valor acima de 3, sendo assim, o corante natural atingiu padrões excelentes, procurados pelas indústrias. As razões para ter alcançado esse valor são que a diluição foi bem realizada e o urucum reagiu bem com a fibra de algodão.

O mordente aplicado às fibras tingidas foi eficiente, pois ambos os corantes aderiram totalmente ao tecido.

\section{CONCLUSÕES}

No comparativo com o corante natural extraído do urucum e o corante artificial Laranja Sidercrom, o tecido tingido com o corante natural obteve melhores resultados, tanto no teste de solidez à lavagem quanto na análise de cor, no comparativo com a Escala Pantone, frente diferentes iluminações.

$\mathrm{Na}$ análise de cor, grandes variações podem ser perceptíveis visualmente, e as indústrias têxteis evitam esses tipos de resultados em seus processos, para obter tecidos tingidos que continuem com a mesma cor independente da iluminação do ambiente.

No teste de solidez à lavagem, a boa aderência do corante ao tecido é fundamental, para que se mantenha sua mesma tonalidade após os processos de lavagem, além de evitar com que o tecido acabe liberando corante, o que pode manchar outras peças de roupa que estejam juntas em uma mesma máquina de lavar roupas. Uma das possibilidades do corante artificial ter ficado em excesso no tecido (e liberado corante durante o teste) é a má lavação após a etapa de tingimento, ou a má diluição do corante durante o tingimento. O tecido tingido com o corante natural mostrou que a aderência ao tecido foi excelente.

\section{REFERÊNCIAS}

Escola SENAI "Francisco Matarazzo". Beneficiamentos Têxteis: lavanderia, tingimento de peças confeccionadas. São Paulo, 2004.

FERREIRA, Eber Lopes. Corantes naturais da Flora Brasileira: guia prático de tingimento com plantas. Curitiba: Optograf, 1998.

FRANCO, C. F.O. Corantes naturais de urucum (Bixa orellana L.) no tratamento da hiperlipidemia e câncer em animais. Tese de Doutorado (Programa de Pós-Graduação em Bioquímica Agrícola da Universidade Federal de Viçosa), 2008. 193 p. 
KASSAB, Alvaro Luiz. Algodão: do artesanato indígena ao processo industrial. São Paulo: Íncone, 1986.

MENDA, M. Química Viva - corantes e pigmentos. Disponível em: $<$ http://crq4.org.br/default.php? $\mathrm{p}=$ texto.php\&c=quimicaviva_corantespigmentos $>$. Acesso em 20 abr. 2014.

NBR ISO 105-A01 - Ensaios de solidez da cor - parte 01: princípios gerais do ensaio. ABNT, 07 ago. 2006.

105-A02 - Ensaios de solidez da cor - parte 02: escala de cinza para avaliação da alteração da cor. ABNT, 07 ago. 2006.

105-A03 - Ensaios de Solidez da Cor - parte 03: escala de cinza para avaliação da transferência da cor. ABNT, 07 ago. 2006.

PANTONE. About Pantone: who we are. Disponível em: <http://www.pantone.com/ pages/pantone.aspx?pg=19306>. Acesso em 24 de ago. de 2013.

ROCHA, Julio Cesar. ROSA, André Henrique. CARDOSO, Arnaldo Alves. Introdução à Química Ambiental. 2.ed. Porto Alegre: Bookman, 2009.

SELLERINK. Disponível em: <http://sellerink.com.br/blog/tag/modelo-cielab/>. Acesso em 26 abr. 2014.

TEXCONTROL. Disponível em: <http://www.texcontrol.com.br/insumo/lampadas.htm>. Acesso em 26 abr. 2014. 